\title{
The Neuroscience of Pain, and a Neuroethics of Pain Care
}

\author{
James Giordano
}

Received: 19 January 2009 / Accepted: 21 January 2009 /Published online: 11 February 2009

(C) Springer Science + Business Media B.V. 2009

\begin{abstract}
Neuroscience, together with a broadened concept of "mind" has instigated pragmatic and ethical concerns about the experience and treatment of pain. If pain medicine is to be authentic, it requires knowledge of the brain-mind, pain, and the relative and appropriate "goodness" of potential interventions that can and/or should be provided. This speaks to the need for an ethics that reflects and is relevant to the contemporary neuroscience of pain, acknowledgment and appreciation of the sentient being in pain, effects of environment and value(s), and the nature of healing. It may be that neuroethics provides this viable meta-ethic for pain care. This essay describes how an integrative neuroethics of pain care allows, if not obligates, alignment of facts, values, and moral attitudes as a continuing process of re-investigation, analysis, and revision of what we know (and don't know) about brains, minds, selves, and how we regard and treat the painient.
\end{abstract}

J. Giordano $(\bowtie)$

Departments of Medicine and Neurosciences,

Center for Clinical Bioethics,

Georgetown University Medical Center,

4000 Reservoir Rd, Bldg D,

Washington, DC 20057, USA

e-mail:.jg353@georgetown.edu

J. Giordano

Center for Neurotechnology Studies,

Potomac Institute for Policy Studies,

Arlington, VA 22203, USA

\section{The Neuroscience and Neurophenomenology of Pain}

“...ask a man...a reason why he hates pain, it is impossible he can ever give any. This is an ultimate end..."

\section{David Hume [1]}

An enhanced understanding of neuroscience together with a broadened concept of "mind" has instigated pragmatic and ethical concerns about the experience of pain [2]. Such concerns must account for both the neural process of pain, and its proximate and more durable effects - as neural event and cognitive and emotional experience-that occur in painient beings existing within particular environments, communities and cultures. The experience of pain occurs through the activation of hierarchical networks that develop and may vary as a consequence of genotypic, phenotypic and environmental interactions throughout the lifespan of each individual $[3,4]$. The newly popular phrase of "...see one brain, see one brain" would thereby suggest the improbability, if not impossibility of the colloquialism "...I feel your pain" as it is likely that the sensation and experience of pain are individually variant, subjective, and in reality, knowable only to the one who suffers. In essence, we cannot "feel" an other's pain any more than we can know what it is like to be another being 
[5]. Rather we can only recognize or know others' experiences in relation to our own subjectivity $[6,7]$. We do this through 1) objectifying others' experiences by applying intellectual knowledge of common processes that are equivalent or similar in ourselves and others (i.e.- phenomenological relativism), 2) perception of some set of knowable reactions, responses and/or semiotics, and/or 3) the direct explanation of subjective experience(s) by others. This makes pain assessment pragmatically and morally difficult in those situations in which linguistic and/or communicative barriers exist, such as between cultures; when dealing with patients who are profoundly mentally impaired, demented or obtunded, when dealing with animals, and/or when considering the possibility of pain and suffering in nonorganic, "artificially intelligent" entities.

\section{The Possibilities and Limitations of Neuroscience: Implications for a Neurophilosophy of Pain}

"... Nature is only showing us the tail of the lion, but I have no doubt that the lion belongs to it even though, because of its large size, it cannot totally reveal itself all at once..."

\section{Albert Einstein [8]}

Knowledge of the development, structure and function of the systems that mediate pain and analgesia is vital, but it is equally important to recognize the boundaries of objective information, and what this infers about the uncertainty of others' subjective experience. The imperative to evaluate and treat pain and suffering has been a major incentive for the development of new medical techniques and technologies [9]. Perhaps neurotechnology will one day allow the completely objective assessment of pain (and its experience). To date, however, this has not been the case, and even if this were possible, we still must confront the limitations, burdens, and risksalong with the benefits-of any technologic advance, and the information it may deliver [10].

Current neuroscience informs that the relationships of brain, mind and self are not linear or wholly deterministic, and this expanding epistemologic framework may be the basis of a new (neuro) philosophy of pain that more clearly defines both what pain is, and what such definitions of pain mean with regard to our conduct toward both human and non-human others. An iterative understanding of the structure and function of various organisms' nervous systems (and of the human organism at various stages and states of existence) allows-or perhaps more accurately dictates-consideration that particular organisms can, and likely do feel pain [11]. Given that pain cannot be directly assessed solely through objective means, in the absence of subjective reports and descriptions, the fact that an organism has the capacity to feel pain must both satisfice our belief that they experience pain, and guide our treatment of such (potential for) pain and suffering in accordance with some form of precautionary principle. This would base pain care upon a naturalistic (neuro) philosophy that is built upon the most current epistemic capital, and acknowledges the experience of pain as one of the most elemental qualities of anthropological and ethical concern.

For now, perhaps, this may be enough to compel an overarching obligation to treat pain. Yet, if the core incentive of neuroscientific inquiry is not simply knowledge "for knowledge's sake", but the acquisition of knowledge that can be applied toward the achievement of an identifiable, humanitarian purpose, then moral consideration is required to determine not just "why" but "how" care for those in pain must be rendered so as to enact individual and social good [11].

\section{Toward a Neuroethics of Pain Care: Purpose and Potential}
“...analysis makes for unity, but not necessarily goodness..."

Sigmund Freud [12]

This speaks to the need for an ethics that both reflects, and is directly relevant to the current neuroscience of pain, acknowledgment and appreciation of the sentient being in pain, effects of cultural value(s), and the nature of healing; in other words, a neuroethics of pain care that is consistent with both of its major "traditions", so as to consider 1) the neural bases for and of moral decision-making, and 2) the moral basis and ethics of neuroscientific research, applications and related practice(s). 
To be sure, a number of ethical issues arise at the intersection of neuroscience, medicine and society, and many of these are directly relevant to pain care. For example, the principle of respect for autonomy has played a central role in much of contemporary bioethical thought, based upon varying constructs of the "self" [13]. In the strictest sense, autonomy can be understood to be 1) a particular kind of potentiality of being, 2) the ability of such a being to make independent decisions and actions, and 3) the negative right of refusal [14]. Autonomy in the first sense (i.e.- a being as an autonomous moral subject) is in some ways related to the manifestations of a being's independent decisions, and actions [11].

But who (or what) is a moral subject? What of those circumstances in which the level of neural function makes a being unable to act autonomously? This often occurs because of individuals' immaturity (e.g.- neonates, young children), not being fully conscious, or being mentally impaired. Very often, these individuals also cannot express their sentience or pain. Because of this, should we not regard pain in the very young, very old, and the very sick? And what of non-human pain? Probably, like never before, an understanding of animal nervous systems has allowed a consideration of the possibility of pain equivalence in animals, if not of animal minds more broadly, and this latter possibility has initiated dispute about previously held notions of consciousness, mentation, autonomy, and moral value [15-18].

If this neuroscientifically-informed epistemology is to be applicable to, and engage the philosophical domains of anthropology and ethics, we must also recognize that our relationships to any and all other (human and even non-human) beings are not uniform [19]. While we are learning more about the relative capacities of other brains and other minds, asymmetries still exist in our relationships with others based upon their ability to exert autonomous action, level of dependence, and vulnerabilities, and there has been a renewed call to acknowledge this relational asymmetry and tend to those who are vulnerable [20]. In this way, the moral imperative to treat pain and alleviate suffering is not directed at pain as an object, but rather can be seen as a regard for the impact and effects of pain upon a sentient being who is the subject of our respect $[21,22]$. Clearly, the heightened vulnerability of the pre-nate, neonate, young, infirm, obtunded/ vegetative, and aged (as well as non-human sentient beings) strengthens our responsibility for their care.

Such respect reflects a reverence for the experience and value of life in both oneself and others [23] and has been seen as a fundamental characteristic of medicine [24]. In upholding a regard for the "...power of nature, enigma of life, health, pain, [and] suffering" it provides a basis to appreciate both what has the potential to harm, as well as what is good, and thereby “... directs...good intentions and actions" [19]. It is this latter dimension of reverence that guides beneficence [25].

When enacted within pain care-as a medical profession-such beneficence entails striving toward the ends of providing right and "good" treatment to patients [26, 27]. I argue that if pain medicine - as a practice - is to be authentic, it requires knowledge of 1) the brainmind, 2) pathology of pain, 3) available treatments that could possibly mitigate the harm(s) incurred by pain, and 4) the being who is the pain patient, so as to discern (a) the nature and extent of such harms, (b) the relative and appropriate "goodness" of potential interventions, in order to (c) determine what care can and should be provided [28].

Still, defining what is "good" in a pluralized population can be problematic, and becomes ever more so given the imperative to establish a framework for ethically sound, globalized pain care [29]. The diversity of patients' and physicians' values, various exigencies, and general uncertainties that are the reality of the medical relationship and clinical encounter are such that rarely (if ever) do circumstances allow for consideration-or use-of a simple definition of the good, or any given principle with "all things being equal" [30]. Such discord is often directly related to the scope of the social sphere in which health care is provided. Characteristically, the larger the recipient population, the greater the potential and likelihood for the diversity of circumstance(s) and values, and dissonance in such values [31].

\section{Neuroethical Questions and Issues in Pain Care}

“...man was not born to solve the problems of the universe, but to put his finger on the problem and then keep within the limits of the comprehensible..."

Johann Wolfgang von Goethe [32] 
Considering the nature of the "good" of pain care in neurocentric contexts gives rise to several fundamental questions. For example, is there some threshold of pain and suffering that can or should be validated in order to incur and/or justify clinical intervention? At what point does the treatment of pain and suffering become "excessive" and would such intervention be considered "enhancement"? Can neuroscience contribute this metric or rule? To what level(s) might we take diagnostics and therapeutics? Given the capacities and limitations of neuroimaging (e.g.- fMR, fNIR, PET, SPECT, mEEG, etc) what can we realistically expect this technology to yield in pain medicine, and how can we employ these methods so as to avoid 1) what Bennett and Hacker call the mereological fallacy [33], 2) the error of attributing antecedents to the consequential [34], and/or 3) being seduced into the lure of what Ludwig Wittgenstein referred to as "picture thinking" $[35,36]$ ?

Similarly, we must be cautious when employing neurogenetic information to diagnose the pre-disposition or likelihood of pain syndromes, so as to 1) avoid oversimplification of genotype-phenotype-disorder relationships; 2) assume full responsibility to use this information equitably and with appropriate confidentiality in order to prevent social, economic, and/or vocational stigmatization, and disproportionate under-allocation of insurance benefits, and 3) address the problems that arise when diagnosing disorders that cannot be cured.

In addition, we must confront the crucial questions of neural stem cell research [37], and the use of stem cells in pain medicine. However, the stem cell debate is but one of the contentious issues that surround the possible trajectories of neural transplantation [38]. While human-human and animal-human (i.e.- xenograft) transplantation techniques and technologies may offer considerable promise for generating and remodeling new neural pathways, we must ask what extent of new tissue is required to affect the entirety of the neural network (that might constitute operational definitions of mind and self). The use of exogenous material to restore or repair neural function is not limited to living tissue, and we must also examine the benefits, difficulties and problems that arise from the direct interface of technology and human neural systems (e.g.- transcranial magnetic stimulation, implanted bioelectric devices, nano-neurotechnology), and the iterative 'cyborgization' of the human body. While such notions of cyborgization have traditionally been viewed as the stuff of science fiction, Francis Fukuyama [39] and Chris Gray [40] note that biologically-relevant machines have already become the norm throughout many domains of society, and Moore's theorem (viz.the advancement of technologies that are based upon the multiplication of computer-based applications and derivatives) predicts this machine interfacing to progress with fluidity and rapidity. For sure, each and all of these developments can contribute to the extant issues in the treatment of pain [41], and have both utopian and dystopian potential [42].

\section{Proceeding with Prudence}

“...virtue in itself is not enough; there must also be the power to translate it into action."

Aristotle [43]

It may be that neuroethics provides a viable metaconstruct for pain care-providing illustration of the facts and possibilities, as well as grounding moral decisions to a naturalistic regard for neural processes involved in moral cogitation, sentience, self-reflection and the experience of pain. This neuroethics would need to acknowledge the uniquity of the individual, and must take into accord the process(es) by which cognition and emotions contribute to moral constructs and actions. I have previously opined, and re-state here that an agent-based ethics that is critically reliant upon the virtue of practical wisdom may be most functionally viable [27, 44], not because other ethical systems are invalid, but rather because it comports well with our current understanding of neural mechanisms of decision-making and social interaction [45]. If nothing else, practical wisdom must strive to be "operationally beneficent" taking into accord relational asymmetry and subjective appreciation for the phenomenal experience of others. Frankena's conceptualization of multi-leveled beneficence (ranging from the obligatory to the supererogatory, and from the individual to social) [46], coupled to Pellegrino and Thomasma's description of how the acts of medicine affect the multi-dimensional flourishing of each patient as a moral agent [47], allows for a broader, more useful understanding of "good", and how it could and should be enacted (within both pain 
medicine and societies). This beneficence 1) encompasses non-harm through a reverent regard for each sentient and painient individual, and thereby 2) affords respect for each individual's agency, autonomy, intrinsic worth and environmental and cultural-nestedness.

Such consideration would compel the prudent use of the most current scientific knowledge to expand and sustain the need for, and provision of safe, effective, and equitable pain care. To do this may require a more integrative approach that allows - if not obligatesongoing alignment of facts, social values, and moral attitudes as a continuing process of re-investigation, analysis, and revision of what we know and don't know about brains, minds, and selves, and how we regard and treat the painient. In its naturalizing quality, a neuroethics of pain care may achieve this equilibrium, as it would tend to reflect the relatedness of science and ethics, such that science depends upon philosophy to provide perdurable questions of ethical import, and ethics depends upon the sciences for information about how - and upon which - moral judgments can best be made [48]. In this way, it becomes clear that both neuroethics and pain medicine must rely upon new scientific information and knowledge, meet the challenges posed by advances in scientific understanding and technology, and work to address the ever-widening and-deepening questions, issues and imperatives that these developments are likely to generate.

Acknowledgements This work was funded in part by a grant from the Laurance S. Rockefeller Trust.

\section{References}

1. Hume, D. 1998. In: An enquiry concerning the principles of morals, ed. Tom Beauchamp, 93. Oxford: Oxford University Press.

2. Giordano, J. 2008. Complementarity, brain-mind, and pain. Forschende Komplementarmedizin 15: 2-6.

3. Giordano, J. 2008. Maldynia: chronic pain as illness, and the need for complementarity in pain care. Forschende Komplementarmedizin 15: 277-281.

4. Morris, D.B. 1998. Illness and culture in the postmodern age. Berkeley: University of California Press.

5. Nagel, T. 1979. Mortal questions. Cambridge: Cambridge University Press.

6. Dilthey, W. 1990. Gesammelte Schriften V. Band, Stuttgart: BG Teubner Verlagsgessellschaft.

7. Grondin, J. 1995. Sources of hermeneutics. Albany NY: State University of New York.

8. Einstein, A. 2000. In: The expanded quotable Einstein, ed. Alice Calaprice, 232. Princeton: Princeton University Press.
9. Giordano, J. 2008. Technology in pain medicine: research, practice, and the influence of the market. Practical Pain Management 83: 56-58.

10. Jonas, H. 1985. The imperative of responsibility: In search of an ethics for the technological age. Chicago: University of Chicago Press.

11. Niebroj, L., D. Jadamus-Niebroj, and J. Giordano. 2008. Toward a moral grounding of pain medicine: consideration of neuroscience, reverence, beneficence, and autonomy. Pain Physician 11: 7-12.

12. Freud, S. 1966. In: The Viking book of aphorisms. Auden, W. H. and Louis Kronenberger 340. NY: Dorset.

13. Miller, B. 2004. Autonomy. In: Encyclopedia of bioethics, 3rd. ed., vol. 1, ed. SG Post, 246-251 NY: Thompson.

14. Kant, I. 1963. Lectures on ethics. Translated by L. Infield, NY: Harper and Row.

15. Sorabji, R. 1993. Animal minds and human morals: Origin of the Western debate. Ithaca, NY: Cornell University Press.

16. Radner, D., and M. Radner. 1996. Animal consciousness. NY: Prometheus Books.

17. Ryder, R. 1989. Animal revolution: Changing attitudes towards speciesism. Blackwell: Oxford.

18. Kant, I. 1998. Groundwork for the metaphysics of morals, ed. Mary Gregor. Cambridge: Cambridge University Press.

19. Schweitzer, A. 1936. The ethics of reverence for life. Christendom 1: 225-239.

20. Ving, V. 1993. The coming technological singularity: how to survive in the post-human era. Whole Earth Review Winter. Available online at http://www-rohan.sdsu.edu/ faculty/vinge/misc/singularity.html.

21. Gupta, A., and J. Giordano. 2007. On the nature, assessment, and treatment of fetal pain: neurobiological bases, pragmatic issue, and ethical concerns. Pain Physician 10: 525-532.

22. Ryder, R. 2001. Painism: A modern morality. London: Centaur.

23. Woodruff, P. 2002. Reverence. NY: Oxford University Press.

24. Giordano, J., and J. Pedroni. 2007. The legacy of Albert Schweitzer's virtue ethics within a contemporary philosophy of medicine. In Reverence for life revisited: The legacy of Albert Schweitzer, eds. D. Ives, and D. ValoneNewcastle: Cambridge Scholars' Press.

25. Giordano, J. 2006. Agents, intentions and actions: Moral virtue in pain medicine. Practical Pain Management 6: 76-80.

26. Pellegrino, E. 1999. The goals and ends of medicine: How are they to be defined? The goals of medicine, the forgotten issues in health care reform, eds. Mark Hanson and Daniel Callahan, 55-68. Washington, D.C.: Georgetown University Press.

27. Giordano, J. 2006. Moral agency in pain medicine: philosophy, practice and virtue. Pain Physician 9: 4146.

28. Giordano, J., and M. Schatman. 2008. A crisis in chronic pain care-An ethical analysis. Part two: proposed structure and function of an ethics of pain medicine. Pain Physician 11: 589-595.

29. UNESCO 2008. Universal Declaration on Bioethics and Human Rights. http://unesdoc.unesco.org/images Accessed 14 July 2008.

30. Clouser, K.D., and B. Gert. 1999. Concerning principlism and its defenders: Reply to Beauchamp and Veatch. In Building bioethics, ed. L. Kopelman, 183-199. London: Kluwer. 
31. Herskovits, M. 1973. Cultural relativism: Perspectives in cultural pluralism. NY: Vintage Books.

32. Goethe, J.W. 1966. In: The Viking book of aphorisms. Auden, W. H. and Louis Kronenberger 339. NY: Dorset.

33. Bennett, M., and P. Hacker. 2003. Philosophical foundations of neuroscience. Oxford: Blackwell.

34. Uttal, W. 2003. The new phrenology: The limits of localizing cognitive processes in the brain. Cambridge: MIT.

35. Wittgenstein, L. 1958. The blue and brown books: Preliminary studies for the 'Philosophical Investigations'. NY: Harper and Row.

36. Wittgenstein, L. 1961. Tractatus logico-philosophicus. David Pears and Brian McGuinesss (trans). London: Routledge, Kegan Paul.

37. Kass, L. 2004. Monitoring stem cell research. Report of the President's Council on Bioethics. Washington, D.C.: US Gov Printing Office.

38. Freed, W. 1999. Neural transplantation: An introduction. Cambridge: MIT.

39. Fukuyama, F. 2002. Our post-human future: Consequences of the biotechnology revolution. NY: Farrar, Straus and Giroux.

40. Gray, C. 2001. Cyborg citizen: Politics in the posthuman age. NY: Routledge.
41. Giordano, J. 2008. Ethics in and of pain medicine: constructs, content, and contexts of application. Pain Physician 11: 1-5.

42. Gordijn, B. 2005. Nanoethics: from utopian dreams and apocalyptic nightmares towards a more balanced view. Science and Engineering Ethics 114: 521-533.

43. Aristotle 1944. Politics. Aristotle in 23 volumes, Vol. 21, translated by Harris Rackham. Cambridge, Mass: Harvard University PressLondon: William Heinemann Ltd.

44. Giordano, J. 2007. Pain, the patient and the physician: Philosophy and virtue ethics in pain medicine. In: Ethical issues in chronic pain management, ed Michael Schatman, 1-18. NY: Informa.

45. Casebeer, W. 2003. Moral cognition and its neural constituents. Nature Reviews Neurosciences 4: 841-846.

46. Frankena, W. 1982. Beneficence in an ethics of virtue. In Beneficence and health care, ed. E. Shelp, 63-81. Dordrecht: Reidel.

47. Pellegrino, E., and D. Thomasma. 1987. For the patient's good: The restoration of beneficence in health care. NY: Oxford University Press.

48. Baggini, J., and P. Fosl. 2007. The ethics toolkit: A compendium of ethical concepts and methods. 190-191. Oxford: Blackwell. 